\title{
Un enterratorio procedente del mineral de El Salvador (III Región)
}

Ivo KuZManić ${ }^{1}$ Y JULIo SANHUEZA ${ }^{2}$

\section{Introducción}

La intención de participar en el Subsimposio "Secuencia de asentamientos e indicadores del Período Cerámico de la Subárea Circumpuneña" obedece fundamentalmente al criterio de entregar aportes inéditos en torno al sector más meridional de la subárea en referencia que, en general, adolece de información suficiente en términos culturales preeuropeos.

Si bien es cierto que los autores de este trabajo no tuvieron participación directa en el rescate de las evidencias, la información recuperada en el curso de la investigación permite señalar que los datos reportados son lo suficientemente seguros como para establecer algunas consideraciones en relación a la identidad cultural del material.

Dadas las limitaciones de espacio y por tratarse de un trabajo en proceso, se restringe la información a los sectores más relevantes del estudio.

\section{Historia y características del hallazgo}

La evidencia aquí presentada consiste en un fardo funerario con su contexto procedente del mineral de El Salvador, ubicado en la Provincia de Chañaral, III Región de Chile. El fardo en cuestión fue donado al Museo de la ciudad de Vallenar a comienzos de 1971 por sus descubridores, la familia Carmona García, quienes en ese tiempo residían en dicho campamento minero (Figura 1a).

El descubrimiento se realizó incidentalmente, a fines de 1970, en el sector nororiente del cerro Indio Muerto, específicamente en la quebrada Las Turquesas (26 ${ }^{\circ} 14^{\prime}$ 'Lat. S, 69 $9^{\circ} 33^{\prime}$ Lat. O aprox.) en lo que hoy es el actual mineral de El Salvador.

Museo Regional de Antofagasta, Antofagasta, CHILE.

2 Universidad Arturo Prat. Casilla 286, Iquique, CHILE.
De acuerdo a los archivos existentes en el museo y previas consultas a los donantes, ha sido posible establecer una reconstrucción aproximada de las condiciones originales del enterratorio y su material cultural asociado. Así, el fardo se encontró depositado en un pequeño foso vertical de sedimento calcáreo, asentándose sobre un sustrato rocoso de escasa profundidad; entre la base rocosa y el cuerpo se había colocado una manta o poncho bicromo (33-1-82) en tanto que el fardo estaba atado dentro de una red de cordeles de lana $(37,38,39-1-82)$ que lo rodeaban completamente. El cuerpo (51-1-82) del individuo se cubrió con una túnica (32-1-82) sobrepuesta, dejando al descubierto solamente la cabeza.

Hacia un costado y en la espalda poseía un arco (3-182 ) con sus venablos (06-20-1-82) y un sustentador (1-1-82), este último utilizado aparentemente para colocar al fardo dentro de la fosa funeraria.

En el costado izquierdo, bajo el brazo izquierdo, a nivel de las costillas y apegado a la túnica se ubicaba un gancho de atalaje (22-1-82) amarrado en ambos extremos por uno de los cordeles que constituían la red de envoltura.

Sobre la cabeza, poseía un tocado de lana cubierto con plumas de color rojo (40-1-82) y un sujetador de hueso para el peinado (26-1-82), probablemente las dos fajas (31-1-82) y (34-1-82) encontradas estaban puestas sobre las rodillas.

El resto del ajuar, una talega polícroma (28-1-82), dos bolsas o costales decorados (29-30-1-82), una bolsa (35-1-82), una alforja (36-1-82), un atado de lana con vegetales (41-1-82), cinco bolsitas con turquesas (42-46-1-82), dos bolsitas de cuero (47-48-1-82), tres trozos de charqui (49-1-82), una pata de camélido (50-1-82), un tiesto cerámico (27-1-81), un collar de turquesas (25-1-82), dos

\footnotetext{
3 La numeración entre paréntesis corresponde al número de inventario de la pieza.
} 
cestos decorados (23-24-1-82), un artefacto de madera no identificado (21-1-82), una espátula (05-1-82), un morterito (04-1-82) y una tableta para rapé (02-1-82), se encontraron distribuidos a los pies y a los costados del fardo. Probablemente las bolsitas con turquesas estaban dentro de la bolsa (35-1-82).

\section{Antropología física}

La descripción anatómica señala que el cuerpo corresponde al de un individuo momificado naturalmente (deshidratado), conservado sin mayores alteraciones (escasos signos de deterioro). De acuerdo a la inspección del cuerpo, se comprobó sexo masculino, observándose el pene y escroto con vello pubiano no muy abundante. En relación a su dentición y por registros anatómicos generales posee un rango de edad de adulto maduro.

En posición sedente genuflexa, presenta una profunda curvatura de la columna vertebral con proyección de la cabeza hacia adelante, enfrentando las piernas; conserva la boca abierta y mandíbula caída, lo que permite observar que la lengua se encuentra descansando en el lado izquierdo de la mandíbula sobre $\mathrm{I}_{2}, \mathrm{C}$ y $\mathrm{PM}_{1}$.

Posee una tupida cabellera en un complejo peinado de trenzas, actualmente muy deteriorado con presencia de liendres (Pediculus capilis).

El brazo y antebrazo izquierdo flectado casi en ángulo recto proyectan el codo hacia adelante tocando el muslo izquierdo, a nivel del tercio medio. La muñeca interior de la mano izquierda roza el costado derecho del tórax.

El brazo derecho no se proyecta, cayendo al costado, aunque se presenta flexionado en la misma angulatura que el izquierdo con cierta rotación hacia adentro; el tercio inferior se encuentra inmediatamente debajo del tercio medio del antebrazo izquierdo y sobre la cadera derecha y el pubis. La mano está recogida y apoyada en la cadera. Las extremidades inferiores se encuentran flexionadas en ángulo agudo, separadas y enfrentando al tórax.

En la pierna izquierda existe una seria fractura expuesta con compromiso óseo, muscular y cutáneo. El peroné está fracturado y dividido a nivel del tercio superior y la tibia se parte a nivel del tercio medio, con exposición de esta porción y parte de la superior por medio de una herida perforante del tejido, mientras que el extremo inferior fracturado del peroné atraviesa internamente los tejidos.

Los pies se encuentran encogidos, conservándose las uñas al igual que en las manos.

En lo que respecta al tipo físico se puede concluir que presenta un cráneo braquicefálico de bóveda mediana, cara ancha (eurieno), órbitas hipsiconcas (altas), nariz ancha (camerrina) y paladar ancho (braquiestafilino), no presenta indicio de deformación craneana. En relación a su estatura, ésta tiene un promedio estimativo de $162.37 \mathrm{~cm}$, con una desviación estándar de $159.38-165.36 \mathrm{~cm}$. Hay un alto registro de caries a nivel de los molares y premolares, aunque no están muy desarrolladas, notándose también grados de abrasión que van del 1 al 3 (no muy pronunciada). En la mandíbula presentó apiñamiento dentario a nivel de $\mathrm{PM}_{1}, \mathrm{C}, \mathrm{I}_{1}$, Ic, derechos e izquierdos. En cuanto a patrones oclusales, se observó sólo Y-5 para ambos $\mathrm{M}_{3}$ mandibulares. Hay registro de diente en pala (shavel shape).

Las observaciones radiológicas realizadas permitieron definir a un individuo politraumatizado. Como ya se indicó, existe una gran fractura en la pierna izquierda, localizada a nivel del tercio medio de la tibia y superior del peroné, está expuesta con rompimiento de los cabos y rotura de la piel; esta herida es de bordes limpios, lo que implica que la muerte se debió producir poco después de que el individuo se traumatizara, ya que no se percibe regeneración ósea. En una vértebra dorsal baja se registra un grave aplastamiento del cuerpo vertebral, seguramente a consecuencia de una compresión axial muy fuerte. Además, se observa una gran luxación a nivel de una vértebra dorsal superior que proyecta todo el tronco superior hacia la sección ventral del individuo. Se suman a esto múltiples fracturas en diversas secciones de las costillas.

\section{Descripción del material cultural}

- Madera

$\mathrm{N}^{\circ}$ : 1-1-82. Sustentador.

Medidas: a) Fragmento con apéndice: $470 \mathrm{~mm}$ de largo, $17 \mathrm{~mm}$ de diámetro.

b) Fragmento sin apéndice: $450 \mathrm{~mm}$ de largo, $22 \mathrm{~mm}$ de diámetro. 
Corresponde a una rama fracturada de color café claro natural, doblada en ángulo obtuso, dando origen a una forma aproximadamente trapezoidal, sin línea de base. Aparentemente ambos extremos estaban amarrados a la red de envoltura del fardo en la espalda del paquete funerario, dejando la sección más estrecha o mango hacia arriba a objeto de permitir la sujeción del fardo mientras era introducido en la fosa.

$\mathrm{N}^{\circ}$ : 2-1-82. Tableta para rapé (Figura $1 \mathrm{~b}$ ).

Medidas: $\quad$ Largo total: $161 \mathrm{~mm}$, ancho máx.: $59.5 \mathrm{~mm}$, grosor máx.: $29.0 \mathrm{~mm}$.

Largo tableta: $\quad 111.5 \mathrm{~mm}$, largo apéndice: $49.5 \mathrm{~mm}$.

Consiste en una tableta de color café oscuro, en donde la tableta corresponde a una aproximación rectangular con una leve inflexión en los costados de la caja (vista frontal). Los bordes laterales e inferior son rectos, presentándose dos concavidades rectangulares en cada borde lateral y una en el centro del inferior, en tanto que el borde superior es más ancho con varias concavidades pequeñas. Se observa una curvatura del cuerpo hacia el apéndice.

El apéndice tallado en volumen corresponde aparentemente a una hibridación-sáurica-ofídica-felínica en actitud de reposo. En torno a toda la figura se observan 14 concavidades de diversas formas, cubriendo las extremidades, lomo y cabeza, conservándose cuatro incrustaciones de pedrería de color verde y blanco.

$\mathrm{N}^{\circ}: 3-1-82$.

Medidas:

Arco.

a) Extremo derecho: Largo $465 \mathrm{~mm}$, sección anteroposterior $19 \mathrm{~mm}$, grosor variable: $6-20 \mathrm{~mm}$.

b) Porción central: Largo $450 \mathrm{~mm}$, sección anteroposterior $23 \mathrm{~mm}$, grosor: $24 \mathrm{~mm}$.

Arco quebrado, supuestamente en tres partes, decorado en pintura roja con franjas negras y blancas. $\mathrm{Su}$ corte es de sección plano-convexa con aguzamiento hacia los extremos.

$\mathrm{N}^{\circ}: 4-1-82$.

Medidas:
Morterito (Figura 1b).

Alt. $59 \mathrm{~mm}$, diám. cuerpo: $30 \mathrm{~mm}$, diám. interno: $23.5 \mathrm{~mm}$.
Corresponde a un pequeño mortero de color café gris de forma hiperbólica, base plana, pared subcóncava, labio recto con el fondo interno cóncavo. Hay una banda de color oscuro de $11 \mathrm{~mm}$ de ancho que circunda horizontalmente el centro exterior del cuerpo.
$\mathrm{N}^{\circ}: 5-1-82$.
Espátula (Figura 1b).
Medidas: Largo total: 154 mm, diám. máx. $14 \mathrm{~mm}$.

Espátula de mango cilíndrico que se transforma su cono truncado hacia el extremo proximal. Presenta un tallado semicónico desde la base del cual surge la pala. Presenta una franja circundante de color negro.

\section{$\mathrm{N}^{\circ}$ : 6- al 20-1-82. Venablos. \\ Medidas: a) Sección superior: Largo prome- dio: $163 \mathrm{~mm}$, diám. promedio: $6 \mathrm{~mm}$. \\ b) Sección inferior: Largo prome- dio: $235 \mathrm{~mm}$, diám. promedio: $8 \mathrm{~mm}$.}

Se trata de 15 venablos compuestos por dos secciones, la superior e inferior conectadas entre sí. La mayoría se encuentran pintados con colores que varían entre el café-rojo-verde-negro, formando franjas de ancho variable que circundan a ambas secciones.

La sección superior presenta en su extremo distal una acanaladura para insertar la punta, en tanto que el extremo proximal se encuentra rebajado para permitir su inserción en el extremo distal de la sección inferior. Generalmente presenta embarrilamiento en el extremo distal. La sección inferior es hueca con una acanaladura en su extremo proximal para asegurar su colocación en la cuerda tensora del arco.

\section{$\mathrm{N}^{\circ}$ : 21-1-82. $\quad$ No identificado (Figura 3c).}

Medidas: a) Cono: Alto: $25.5 \mathrm{~mm}$, diám. sup.: 10 mm, diám. inf.: $14.5 \mathrm{~mm}$, diám. orificio interno: 4-7 mm.

b) Vara: Largo: $128 \mathrm{~mm}$, diám. $5 \mathrm{~mm}$.

c) Tubo: Largo: $140 \mathrm{~mm}$, diám. $10 \mathrm{~mm}$.

Corresponde a un artefacto compuesto por tres piezas, dos de las cuales se unen (vara y cono) y se introducen en el tubo o caña continente. 


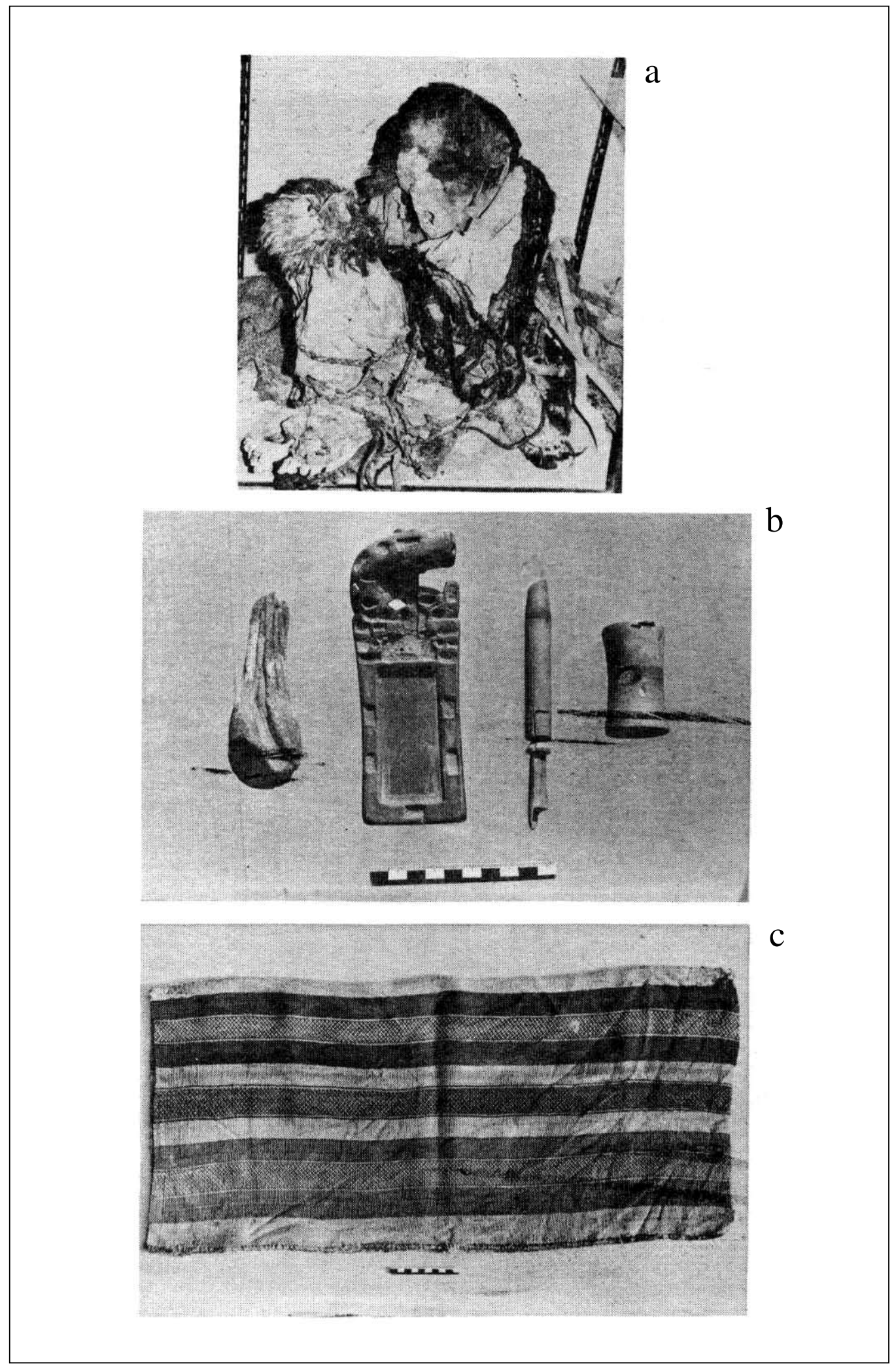

Figura 1. a) Fardo funerario procedente del Mineral de El Salvador; b) Conjunto para alucinógeno; c) Costales 29-30-1-82. 


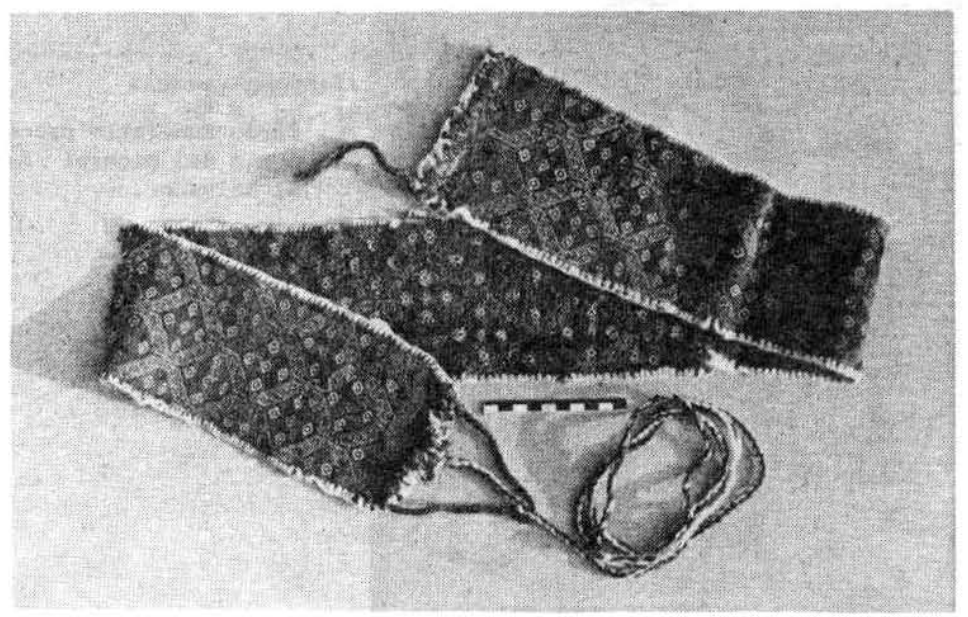

a
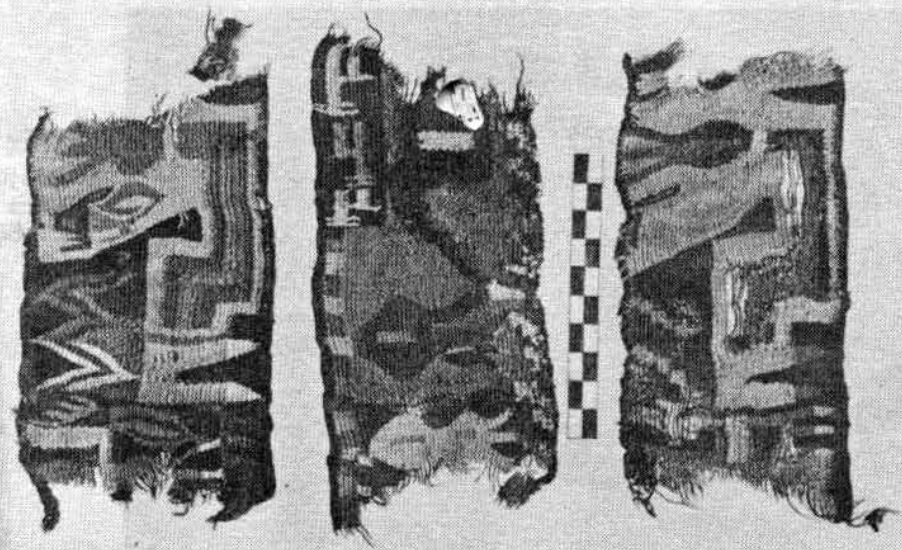

b

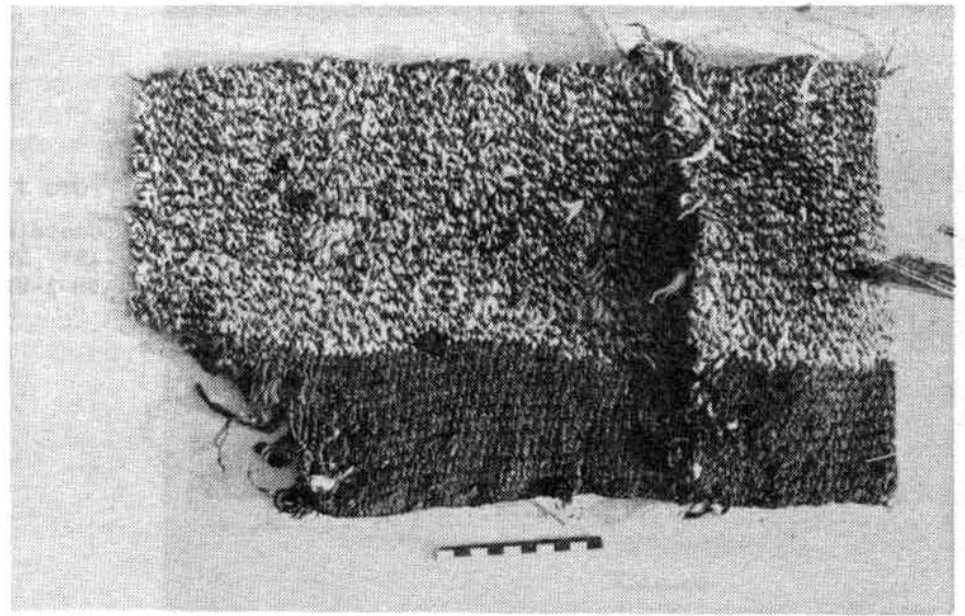

$\mathrm{C}$

Figura 2. a) Faja 31-1-82; b) Faja 34-1-82; c) Alforja 36-1-82. 

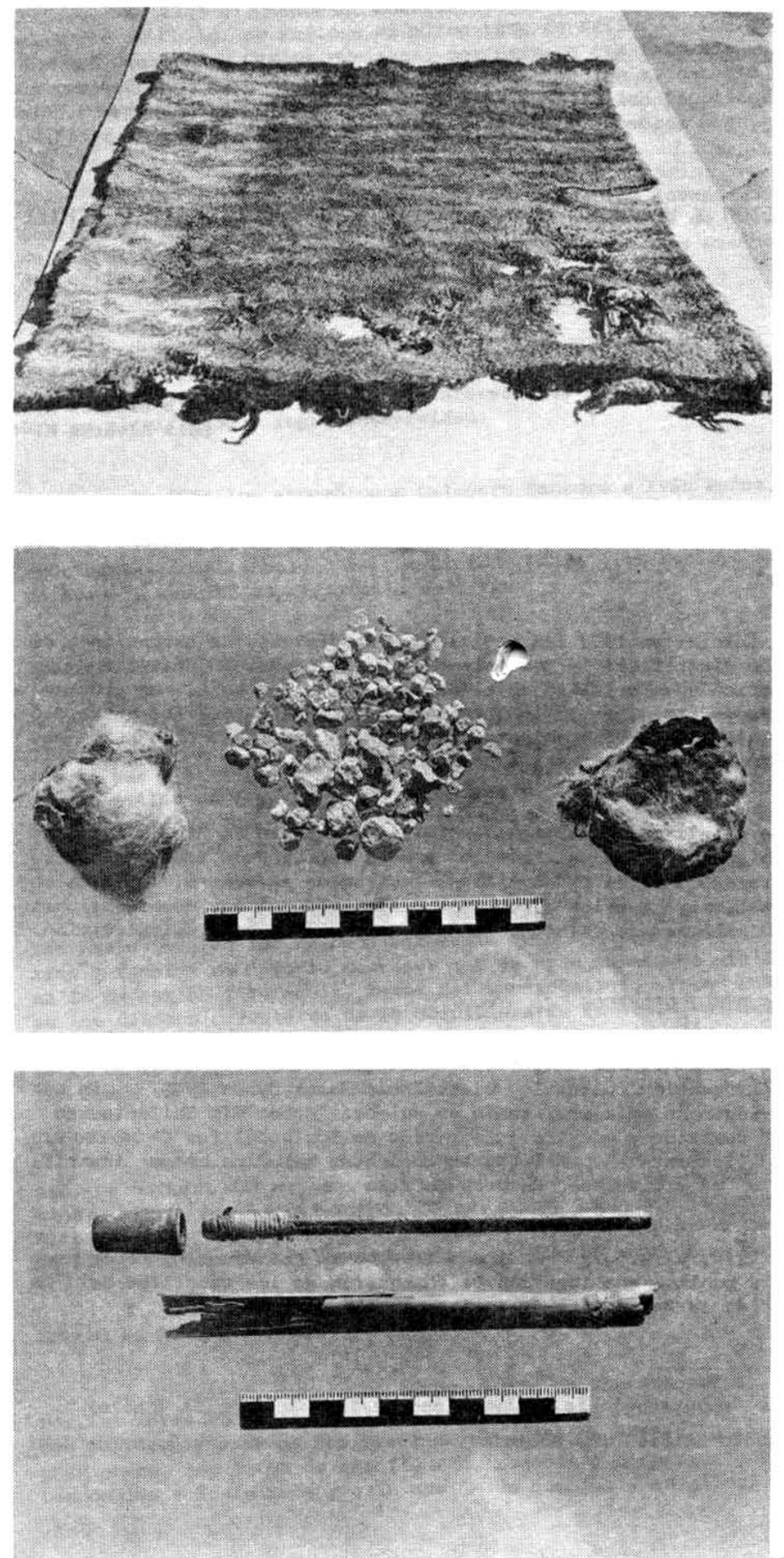

C

Figura 3. a) Manta 33-1-82; b) Bolsitas con mineral 42-46-1-82; c) Cono, vara y caña ahuecada 21-1-82. 
El cono truncado se encuentra perforado centralmente, este orificio desde la base y a una profundidad de $6 \mathrm{~mm}$ posee un reborde interno que actúa como tope. En este orificio se inserta un extremo de la vara embarrilado con fibra vegetal y un hilo torcido de $1 \mathrm{~mm}$ de diámetro cubriendo un ancho circundante de $20 \mathrm{~mm}$.

La vara se encuentra muy pulida y decorada en toda su extensión con figuras incisas rellenas de pintura blanca, originando formas de trébol de tres hojas. El color base de la vara es café.

El tubo continente corresponde a una caña ahuecada.

$\mathrm{N}^{\circ}$ :22-1-82. Gancho de atalaje.

Medidas: $\quad$ Largo interior: $148 \mathrm{~mm}$, largo exterior: $171 \mathrm{~mm}$, diám. antero post.: $24 \mathrm{~mm}$, diám. protub.: $16-20 \mathrm{~mm}$, ángulo abertura: $115^{\circ}$.

Gancho de atalaje con un acodamiento central y dos protuberancias cilíndricas en ambos extremos. Ambos extremos estaban atados a los cordeles de la red de envoltura del fardo.

\section{- Cestería}

$\mathrm{N}^{\circ}: 23-1-82$.

Cesto.

Medidas:

Altura: $78 \mathrm{~mm}$, diám. base: $101 \mathrm{~mm}$, diám. borde: $178 \mathrm{~mm}$, grosor pared: $5 \mathrm{~mm}$.

Tiesto simple, no restringido de base plana, pared convexa, altura variable y labio convexo. Elaborado con técnica de aduja o espiral con armadura (cicloide).

La decoración es interna y externa, con campos similares alternados en colores café claro y oscuro.

Los motivos responden a máscaras o fases antropomorfas y figuras de camélidos estilizados.

\section{$\mathrm{N}^{\circ}:$ 24-1-82. Cesto.}

Medidas: $\quad$ Altura: $35 \mathrm{~mm}$, diám. base: $77 \mathrm{~mm}$, diám. borde: $147 \mathrm{~mm}$, grosor pared: $5 \mathrm{~mm}$.

Escudilla simple, no restringida de base semiplana, pared recta expandida y labio convexo, elaborado con técnica de aduja o espiral con armadura (cicloide).
La decoración es interna y externa con motivos idénticos en ambas caras, presentando una franja color café oscuro circundante sobre el café claro del resto de la pieza.

El motivo principal consiste en bandas verticales paralelas unidas por bandas oblicuas que unen ambos extremos de las bandas verticales.

- Lítico

$\mathrm{N}^{\circ}$ : 6c-1-82. Punta de proyectil.

Medidas: $\quad$ Largo: $18 \mathrm{~mm}$, ancho: $9 \mathrm{~mm}$, espesor: $5 \mathrm{~mm}$.

Artefacto lítico bifacial, facturado en cuarzo coloidal, simétrico de forma triangular, bordes rectilíneos convergentes, base pedunculada con aletas. Se encontró inserta en el venablo 6-1-82.

$\mathrm{N}^{\circ}:$ 25-1-82. Collar.

Medidas: $\quad$ Largo: $330 \mathrm{~mm}$, diám. prom. cuentas: externo variable: $7-9 \mathrm{~mm}$, interno: $3 \mathrm{~mm}$, grosor: 2-8 $\mathrm{mm}$.

Collar compuesto por 20 cuentas verdes de turquesa de formas y tamaños variables, en donde las formas cilíndricas de pared recta o convexas son predominantes. Se encontraron insertas en una cuerda de pelo de camélido de dos cabos, torsión S, cuyo hilado es torsión Z, de color café oscuro.

- Oseo

$\mathrm{N}^{\circ}:$ 26-1-82. Sujetador.

Medidas: $\quad$ Largo: $117 \mathrm{~mm}$, ancho: $14 \mathrm{~mm}$, grosor: $2 \mathrm{~mm}$.

Sujetador de peinado elaborado a partir de un fragmento de costilla con un extremo redondeado y el otro aguzado, presenta una superficie pulida y la otra áspera. Se encontró en la porción occipital derecha de la cabeza.

- Cerámica

$\mathrm{N}^{\circ}:$ 27-1-82. Tiesto.

Medidas: $\quad$ Altura: $92 \mathrm{~mm}$, diám. mayor: $74 \mathrm{~mm}$, diám. borde: $47 \mathrm{~mm}$, grosor: $5 \mathrm{~mm}$.

Tiesto cerámico, simétrico, inflexionado restringido independiente de forma ovaloide-hiperbólica, labio 
irregular convexo, base plana, superficie roja alisada con una capa de pintura roja parcial, pasta oxidante, antiplástico fino.

Presenta una cuerda alrededor del cuello de $420 \mathrm{~mm}$ de largo, de pelo de camélido color café oscuro-café claro de dos cabos, torsión S, con hilado torsión Z.

- Textiles

$\mathrm{N}^{\circ}: 28-1-82$.

Talega.

Medidas: Largo: 290-300 mm aprox.; ancho: $195 \mathrm{~mm}$, ancho boca: $195 \mathrm{~mm}$.

Corresponde a una bolsa talega elaborada en lana de camélido, de forma rectangular listada en colores con rebordes bordados en las orillas laterales y circundando la boca.

Decoración: En ambas caras presenta cinco franjas de color que cubren toda la superficie: a) franja color rojo de $26 \mathrm{~mm}$, b) franja color negro de $45 \mathrm{~mm}$ con líneas paralelas a ambos lados amarillo-ocreblanco, c) franja color rojo de $32 \mathrm{~mm}$, d) franja negra de $5 \mathrm{~mm}$ con líneas paralelas a ambos lados: blanco-negro-blanco-negro-blanco-negro-amarillonegro-amarillo-negro, e) franja roja de $27 \mathrm{~mm}$ y f) bordado de orillas: tipo espina de pescado (Emery 1966 en Ulloa 1982a y b) con secuencia de colores: negro-blanco-amarillo-burdeo.

Sistema de tejeduría:

Densidad de U y T x cm²; U. 26 H., T. 6 p.

Torsión: Hilos de U: Z; hilos de T: Z.

Ligamento; Faz de urdimbre Sistema: Telar.

$\mathrm{N}^{\circ}:$ 29-30-1-82. Costales (Figura 1c).

Medidas: a) 29-1-82: Largo: $880 \mathrm{~mm}$, ancho: $400 \mathrm{~mm}$, ancho boca: $400 \mathrm{~mm}$.

b) 30-1-82: Largo: $920 \mathrm{~mm}$, ancho: $370 \mathrm{~mm}$, ancho boca: $350 \mathrm{~mm}$.

Corresponde a dos bolsas costales rectangulares listadas en bandas longitudinales de diferentes colores, unida por punto festón en las orillas facturadas en lana de camélido. Ambas presentan idéntica decoración en las dos caras, consistente en 11 franjas longitudinales de similar ancho que componen un diseño simétrico de dos franjas lisas orillantes color crema base, dos franjas café oscuro y dos café claro con una banda ajedrezada al centro, dos franjas de color base al centro de la faz, orillando una ajedrezada central más ancha en color rojo y café oscuro.

Sistema de

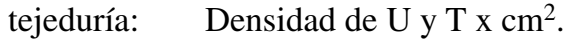

$\mathrm{U}$ : a) $24 \mathrm{~h}$, b) $16 \mathrm{~h}$.

$\mathrm{U}$ : a) $3 \mathrm{p}$, b) $3 \mathrm{p}$.

Torsión: Hilos de U: S, hilos T: S. Ligamento: Faz de urdimbre.

Sistema: Telar.

$\mathrm{N}^{\circ}: 31-1-82$.

Medidas:

Faja (Figura 2a).

Largo: $1120 \mathrm{~mm}$ aprox., largo cordón: $1340 \mathrm{~mm}$, ancho: $120 \mathrm{~mm}$, diám. cordón: $5 \mathrm{~mm}$.

Consiste en una faja policroma cortada en tres secciones. Se encuentra orillada en punto festón y los extremos están limitados por terminaciones de entrelazado abrupto a la trama y la urdimbre y reforzado por el punto festón orillante de los laterales. En sus extremos tuvo dos cordones.

El diseño de la decoración está basado en diferentes coloraciones de la trama base y suplementaria que configuran dibujos geométricos rectilíneos conformando rombos, doble ganchos y hexágonos. La policromía está basada en el café, azul, verde, rojo, amarillo, blanco.

El cordón está formado por un cuerpo central trenzado de color café oscuro y crema, sujeto con un nudo de lazada al extremo de la faja.

Sistema de tejeduría:

Densidad de U y T x cm²; U: 20 $\mathrm{h}, \mathrm{T}: 30 \mathrm{p}$.

Torsión: Hilos de U : Z; hilos de T: Z.

Ligamento: Faz de trama, con trama suplementaria.

Puede decirse que presenta un sistema de "brocado" en que los dibujos geométricos se realizan alternando pasadas de hilo decorativo con pasadas de trama básica (Portillo 1976).

Sistema: Telar.

$\mathrm{N}^{\circ}:$ 32-1-82. Túnica.

Medidas: $\quad$ Largo: $1000 \mathrm{~mm}$, ancho: $960 \mathrm{~mm}$, diám. boca manga: $185 \mathrm{~mm}$, largo bordado base cuello: $40 \mathrm{~mm}$. 
Corresponde a una túnica café crema, elaborada en lana de camélido de forma rectangular, lisa, supuestamente con cuello en "V", sin mangas, con uniones laterales simples. La decoración se manifiesta en la base (orilla inferior), así como en los bordes y base del cuello, presentando bordado tipo "espina de pescado" (Emery 1966 en Ulloa 1982a y b). La orilla inferior presenta una secuencia de tres puntadas de color rojo con hilo doble, intercaladas por tres negras, y luego tres verdes y así sucesivamente.

El cuello conserva dos fragmentos de orillas delanteras con este bordado, un hilo verde y luego rojo. En la base del cuello hay una línea de $8 \mathrm{~mm}$ en donde se observa una línea verde, intercalada por puntadas verde-negro, una línea intercalada de rojo y negro y una línea negra.

Sistema de tejeduría:

Densidad de U y T x cm²; U: $17 \mathrm{~h}$, T: $10 \mathrm{p}$.

Torsión: Hilos de U: S, hilos de T: S.

Ligamento: Faz de urdimbre

Sistema: Telar.

\section{$\mathrm{N}^{\circ}:$ 33-1-82. $\quad$ Manta (Figura 3a).}

Medidas: $\quad$ Alto $1000 \mathrm{~mm}$, ancho: $1300 \mathrm{~mm}$, largo total rectángulo: $2000 \mathrm{~mm}$, largo lados del cuello: $160 \mathrm{~mm}$.

Manta rectangular peluda de lana de camélido color café oscuro-café claro.

La decoración consiste en que a cada lado hay una franja completa de color café oscuro de $60 \mathrm{~mm}$ $(6 \mathrm{~cm})$ ancho, luego una secuencia de 6 hilos café claro, espacio cubierto de $80 \mathrm{~mm}(8 \mathrm{~cm})$, cinco hilos blancos cubriendo de $50 \mathrm{~mm}(5 \mathrm{~cm})$. Las medidas de ancho cubierto son variantes, en la secuencia, desde esta orilla los hilos se van trenzando de manera que queden los bordes café oscuro laterales y se forme un diseño de líneas continuas zigzagueantes en sentido vertical (en forma de " $\mathrm{N}$ " muy pronunciadas) con el color castaño y el blanco. Los vértices de una figura se introducen en el ángulo vertical de apertura de la del color anterior.

De esta forma se dan, línea "N" horizontal café claro, sobre la línea "N" horizontal blanco, y así sucesivamente. El alto de los "N" es aproximadamente $450 \mathrm{~mm}(45 \mathrm{~cm})$ y el ancho entre 140 y $150 \mathrm{~mm}$ $(14 \mathrm{a} 15 \mathrm{~cm})$.
La superficie exterior ha sido cardada para dar el aspecto "peludo". El orificio del cuello es un hojal.

Sistema de

tejeduría:

Torsión cabos (2): S; hilos: Z.

Trenzado plano (en diagonal).

Se compone de 122 hilos que se entrecruzan diagonalmente orillados en un color café oscuro.
$\mathrm{N}^{\circ}: 34-1-82$.

Medidas:
Faja (Figura 2b).

Frag. a) largo: 125-170 mm (irregular), b) largo: $148-165 \mathrm{~mm}$ (irregular), c) largo: 130-155 mm (irregular), ancho: $80 \mathrm{~mm}$.

Corresponde a tres fragmentos de una faja de lana de camélido en tejido muy fino con diseños geométricos polícromos de gran complejidad.

La decoración en los fragmentos a y c es similar y consiste en diseños secuenciales con supuestas figuras híbridas de representación sáurica-ofídicafelínica, de color amarillo con campos rectilíneos angulares rellenos en azul limitando a espacios rojos. Se observa el elemento tripartito en un extremo en color azul con un centro y parte de los apéndices en rojo. El fondo sobre el que se elaboran las figuras es color café oscuro.

$\mathrm{El}$ fragmento $\mathrm{b}$ posee figuras diferentes a los fragmentos a y c, aquí se aprecia nuevamente el elemento tripartito en azul sobre un fondo rojo, también es posible percibir figuras estilizadas de camélidos en café oscuro-café crema.

Sistema de tejeduría:
Podría definirse también como técnica de tapicería, donde la manipulación de hilos de la trama crea diseño; ésta se compone de varios hilos de colores que forman dibujos, por lo que solo cruzan un número limitado y variable de hilos de urdimbre antes de retroceder (D'Harcourt: 1962).

Sistema: Telar.
$\mathrm{N}^{\circ}: 35-1-82$
Bolsa (deteriorada).
Medidas: 
Bolsa rectangular de lana de camélido confeccionada a partir de un resto de costal, decorada con listados de bandas longitudinales. La decoración es similar a los costales presentados anteriormente con un fondo crema sobre el cual hay dos franjas compuestas por una línea ajedrezada central en café oscuro y crema, con cuatro línas limitantes. Se encuentran muy deterioradas y reparadas.

Sistema de tejeduría:

Densidad de U y T x cm²; U: 18 h, T: 5 p.

Torsión: Hilos de U: S, hilos de T: S.

Ligamento: Faz de urdimbre.

Sistema: Telar.

$\mathrm{N}^{\circ}$ : 36-1-82. Alforja (Figura 2c).

Medidas: $\quad$ Largo: $455 \mathrm{~mm}$, ancho: $265 \mathrm{~mm}$, alto bolsillo: $265 \mathrm{~mm}$.

Alforja bicolor rectangular de lana de camélido, con un bolsillo pequeño, elaborada en hilos gruesos. Hecha a partir de un rectángulo que para formar el bolsillo, se dobló y cosió a los lados: 1/3 del largo es de color café oscuro y los otros $2 / 3$ constituyen una superficie continua jaspeada en colores blanco y café oscuro.

Sistema de

tejeduría:

Técnica de telar y un tipo de tapicería (la trama cubre totalmente a la urdimbre). La unión de la sección oscura con la jaspeada se ha hecho mediante un interlocking (Portillo: 1976).

Trama torsión Z, hilado torsión $\mathrm{S}$.

Urdimbre torsión $\mathrm{Z}$, hilados torsión $\mathrm{S}$.

$\mathrm{N}^{\circ}$ : 37-1-82. cordel de color burdeo.

Medidas: $\quad$ Largo: $2416 \mathrm{~mm}$, diám.: $4 \mathrm{~mm}$.

Consiste en un cordel elaborado en lana de camélido que se ha formado por una torsión deficiente de dos hilos. La superficie del cordel está muy cardada y peluda.

Sistema de torsión: tres haces de $1.3 \mathrm{~mm}$ de diámetro, con torsión de haces en $\mathrm{S}$. La retorsión de haces del cordel es Z.

$\mathrm{N}^{\circ}$ : 38-1-82. Cordel corto bicolor.

Medidas: $\quad$ Largo: $1320 \mathrm{~mm}$, diám.: $13 \mathrm{~mm}$.
Cordón grueso elaborado en lana de camélido, de colores naturales que enlazaba en una vuelta simple las piernas y muslos de la momia. Está compuesto por tres haces (bicolor).

Sistema de torsión: cordón: S, haces: (3): Z, hilos: Z.

$\mathrm{N}^{\circ}$ : 39-1-82. Red de cordeles.

Medidas: $\quad$ Largo de cordel grueso bicolor: $800 \mathrm{~mm}$ (podría ser la boca de la bolsa ahora abierta), alto rombos: $140 \mathrm{~mm}$ (prom.), ancho rombos: $110 \mathrm{~mm}$ (prom.), diámetro cordel bicolor: $13 \mathrm{~mm}$, diámetro cordeles: $7 \mathrm{~mm}$.

Cordeles gruesos elaborados en lana de camélido formando una especie de bolsa-red poco definida, de espacios abiertos (rombos). Cumplió función de continente sujetador del fardo funerario. A partir de un cordel bicolor más grueso se amarran oblicuamente los cordeles más delgados, monocromos o bícromos.

Sistema de torsión: Cordones: S, haces (3): Z.

$\mathrm{N}^{\circ}:$ 40-1-82. Tocado.

Medidas: Diám.: $185 \mathrm{~mm}$, espesor: 7- $6 \mathrm{~mm}$, largo máx. plumas: $100 \mathrm{~mm}$.

Semiesfera de hilado grueso, elaborada en lana de camélido con técnica de enlazado simple en espiral. Entre el entrelazado se han introducido vellones de lana café oscura, formando una superficie peluda. En el centro se amarran las plumas rojas de parina (Phoenicoparrus andinis).

Sistema de torsión: Hilado de fibras en torsión S, hilos gruesos Z.

$\mathrm{N}^{\circ}$ : 41-1-82. Atado de lana con vegetales.

Medidas: $\quad$ Ancho: $60 \mathrm{~mm}$, alto: $75 \mathrm{~mm}$.

Paquete de un trozo de tejido de lana de camélido que envuelve a un vellón de lana y al interior contiene ramitas vegetales no identificadas. Se trata de un tejido de malla muy apretada, con una faz exterior felpuda de color rojo.

Torsión hilado: Z, cabos (8): S, cabos (4): Z, cabos (2): S, cordón amarra. Dos cabos torcidos en Z. 
- Misceláneo

$\mathrm{N}^{\circ}:$ 42-46-1-82. Bolsitas con mineral (turquesas). Medidas: Altura promedio: $40 \mathrm{~mm}$, diám. prom.: $50 \mathrm{~mm}$ (Figura 3b).

Se trata de cinco bolsitas de piel de camélido conteniendo trozos de tamaños variables (3-14 $\mathrm{mm}$ ) de turquesa, no trabajada. El peso promedio de cada bolsita es de 30 gr. Se encuentran cerradas con una atadura de nervio animal.

\section{$\mathrm{N}^{\circ}: 47-48-1-82 . \quad$ Bolsita de cuero.}

Medidas: Altura promedio: $100 \mathrm{~mm}$, grosor máx.: $39 \mathrm{~mm}$.

Descripción: Dos bolsas de color gris, elaboradas a partir de un trozo de piel sin pelaje, con replegamiento. Presentan un estrechamiento hacia la boca. Tienen un peso promedio de $50 \mathrm{gr} \mathrm{c} / \mathrm{u}$. No es observable el contenido, pero supuestamente se encuentran muy asociadas al complejo alucinógeno (Bittmann et al. 1978).

\section{$\mathrm{N}^{\circ}$ : 49-1-82. $\quad$ Trozos de charqui. \\ $\mathrm{N}^{\circ}:$ 50-1-82. Pata de camélido.}

\section{Consideraciones}

El área del mineral El Salvador o Indio Muerto, rodeado por extensos tramos desérticos y salares, se inserta dentro de un ámbito de la Puna Salada con escasas posibilidades para el asentamiento humano, empero, los estudios en torno al Camino del Inka (Iribarren y Bergholz 1971, 1972) y a una mina de turquesas (Iribarren 1971, 1972) permiten señalar que el sector en referencia fue enclave de atracción en la explotación de recursos mineros en tiempos prehispánicos. Las evidencias físicas (polifracturas) y culturales asociadas (p.e., bolsitas con turquesas) tienden a demostrar una relación directa del enterratorio aquí presentado con la explotación de la mina citada.

Las características culturales del enterratorio proveniente de la quebrada Las Turquesas indican una indudable matriz de filiación atacameña (oasis de San Pedro de Atacama), a través de elementos diagnósticos, como el grupo de artefactos de madera vinculados a prácticas insuflatorias, el conjunto de textiles expuestos y demás elementos.
Si bien es cierto aún no es posible precisar con toda exactitud la situación cronológica cultural del hallazgo dentro del Período Cerámico de la Subárea Circumpuneña, se perciben algunos indicadores (p.e., madera y textiles) que pueden orientar tal intento. En este sentido el análisis comparativo de los materiales ha permitido establecer algunos parámetros de referencia.

La tableta para rapé reportada no tiene parangón con las existentes en el área de San Pedro de Atacama, por cuanto no se ajusta con precisión a ninguno de los tipos propuestos por Núñez (1963), sin embargo, posee elementos formales y estructurales que admiten homologación. Los orificios nasales del ofidio representado en la tableta 3662 de Quitor 6, asociada a la cerámica San Pedro Negra Casi Pulida (Le Paige 1965) son formalmente equivalentes a los orificios nasales de la figura zoomorfa híbrida de El Salvador. Además, el diseño de las orejas es muy semejante al de varias tabletas con imagen felínica de San Pedro. Con todo, la estructura de la caja, su tamaño y el hecho de que la figura tallada en volumen descanse sobre un panel y no directamente sobre la caja, demuestra con seguridad la impronta de características de diseño típicas en las tabletas de San Pedro (M. C. Torres com. pers.).

La carencia de una secuencia tecnológica-estilística para los textiles del área de San Pedro de Atacama, dificulta las consiguientes correlaciones. La existencia de un fragmento de faja tripartita (ver Figura 1b) elaborada con la técnica de tapicería con un complejo diseño policromo, permite percibir una asociación con Tiwanaku. Si bien es cierto que se observa una pérdida de la rigidez característica de los diseños tiwanaku, no es menos cierto que la presencia en el diseño del elemento tripartito es altamente diagnóstico. La ocurrencia de figuras de camélidos estilizados parece agregar un elemento regional diferencial al tejido.

Una segunda faja policroma tripartita con un sistema de brocado y con diseños compuestos por hexágonos, cuadrados y ganchos, permiten agregar un control cronológico cultural diagnóstico relativo.

La secuencia propuesta por Ulloa (1982a) para los textiles ariqueños demuestra que el ingreso del sistema de tapicería ocurre en la Fase Alto Ramírez (Ulloa 1982a: 100), en tanto que los motivos como figuras geométricas y ganchos redondeados se incorporan 
en la Fase Maitas-Chiribaya (Ulloa 1982a: 101), De cualquier forma, las diversas técnicas aplicadas al conjunto de textiles expuestos como las técnicas de malla, telar y trenzado tienden a agruparse con bastante coherencia a partir de 500 DC (Ulloa 1982a: 104) con una nítida matriz Tiwanaku entre $300-1000$ DC. Si lo anterior es válido, entonces puede postularse un parámetro cronológico entre los 500 años DC a 1000 DC para el fardo en cuestión, lo que equivaldría a colocarlo dentro del Período Medio Tardío de la secuencia cerámica de la Subárea Circumpuneña.

Varias de las técnicas textiles aquí descritas poseen correlaciones ciertas con los textiles de Quitor 2, 5 y 6 (Lindberg 1964) del oasis de San Pedro de Atacama, lo que de una u otra forma viene a afianzar la filiación cultural del hallazgo. Idéntica situación se plantea con algunos textiles expuestos por Oyarzún (1931), Latcham (1938), Rydén (1944), Fuentes (1965) y otros.

La cuestión central radica en explicitar la ubicación de este hallazgo excepcional en el extremo más meridional de la Puna atacameña. ${ }^{4}$ Parece cada vez más seguro que las poblaciones de los oasis de pie de Puna, como San Pedro de Atacama, al recibir influjos de tradiciones altiplánicas como Tiwanaku, se incorporan decididamente a las redes de tráfico interregional, en términos de intercambio (Núñez 1976), expandiendo su esfera de interacción hacia enclaves específicos bastante alejados de las áreas de nucleación. En este sentido, Núñez y Dillehay (1979) han propuesto un modelo explicativo en donde se postula una "movilidad complementaria convergente tiwanaku (400-1000 DC)", a través de desplazamientos de caravanas de camélidos. Durante este período las actividades altiplano-Puna se habían caracterizado por el prestigio económico y teológico del movimiento de caravanas, traslado de excedentes altiplánicos hacia las áreas aledañas y apetencia de bienes parafernálicos de materias primas, bienes tropicales y marítimos por parte de las comunidades de la Cuenca del Titicaca (Núñez y Dillehay 1979: 76). De acuerdo con esto, parece cierto que las comunidades Tiwanaku-atacameñas excedieron los límites locales de explotación a tal punto que la búsqueda y utilización de materias primas minerales para la elaboración de bienes de

4 Si bien aún no ha sido posible confirmarlo, Iribarren (1972: 31) señala con el $\mathrm{n}^{\circ} 13$ a un cementerio indígena saqueado, ubicado en la quebrada Las Turquesas con alrededor de 30 excavaciones. Es muy posible, de acuerdo a las referencias consignadas por nuestros informantes, que el fardo en cuestión proceda de ese cementerio. status (tabletas con incrustaciones, collares, etc.) hicieron que enclaves específicos estimularan el desplazamiento de recuas a grandes distancias. Es así que el enclave minero de El Salvador debió de haber adquirido un rol sustancial en la explotación y abastecimiento de turquesas. Esto ha fundamentado al Dr. Hans Ruppert del Museo Für Völkerkunde de Alemania Federal, a sugerir que los yacimientos de El Abra (Chuquicamata), El Salvador y El Altar (interior de Ovalle), han provisto de turquesas al oasis de San Pedro de Atacama (H. Ruppert com. pers.).

De cualquier forma, la presencia de horquetas de carga, cabezales y reatas (Iribarren 1971, 1972) en los materiales publicados, demuestran que el yacimiento en referencia (mina de turquesas) estaba siendo explotado por comunidades caravaneras especializadas en el tráfico a larga distancia al menos desde el Período Medio Tardío hasta tiempos incaicos.

En consecuencia, y de acuerdo a los datos expuestos, es posible postular que:

1. El fardo funerario se encuentra estrechamente relacionado a las actividades de explotación de la mina de turquesas dadas a conocer en un principio por Iribarren $(1971,1972)$ como de data incaica.

2. Los análisis físico y radiológico, respectivamente, tienden a sugerir que el individuo en cuestión murió como producto de un derrumbe ocurrido en el interior de la mina de turquesas.

3. Los elementos culturales asociados indican con seguridad una matriz cultural proveniente del oasis de San Pedro de Atacama, cuyos rasgos más diagnósticos (madera y textiles) sitúan al hallazgo dentro de un contexto Tiwanaku tardío y/o regionalizado con una cronología relativa entre 500 y 1000 DC dentro de la secuencia del Período Cerámico de la Subárea Circumpuneña.

4. En consecuencia, se postula que la explotación de la mina de turquesas ya es contemporánea a la cronología propuesta para el fardo, y por lo tanto, de data preincaica.

5. El modelo de ocupación responde a la explotación de enclaves mineros específicos de alto prestigio por su exclusividad por parte de comunidades caravaneras a través de una red de tráfico a larga distancia cuya supervivencia ha sido constatada en este caso hasta tiempos incaicos. 


\section{REFERENCIAS CITADAS}

BITTMANN, B., G. LE PAIGE y L. NUÑEZ, 1978. Cultura atacameña. Serie del Patrimonio Cultural Chileno. Colección Culturas Aborígenes. Editorial Gabriela Mistral, Santiago.

D'HARCOURT, R., 1962. Textiles of Ancient Peru and their techniques. University of Washington Press, Seattle.

FUENTES, J., 1965. Tejidos prehispánicos de Chile. Editorial Andrés Bello, Santiago.

IRIBARREN, J., 1971. Una mina de explotación incaica. Boletín de Prehistoria, pp. 267-284.

1972. Una mina de explotación incaica. Depto. de Comunicaciones de Compañía de Cobre Salvador, pp. 55-67. Potrerillos.

IRIBARREN, J. y H. BERGHOLZ, 1971. El Camino del Inka en un sector del Norte Chico. Boletín de Prehistoria, pp. 229-266.

1972. El Camino del Inka en un sector del Norte Chico. Depto. Comunicaciones de Compañía de Cobre Salvador, pp. 5-50, Potrerillos.

LATCHAM, R., 1938. Arqueología de la región atacameña. Prensas de la Universidad de Chile, Santiago.

LE PAIGE, G., 1965. San Pedro de Atacama y su zona (14 temas). Anales de la Universidad del Norte 4.
LINDBERG, I., 1965. Tejidos y adornos de los cementerios Quitor 2, 5 y 6 de San Pedro de Atacama. Revista Universitaria Año XLVIII.

NUÑEZ, L., 1963. Problemas en torno a la tableta de rapé. Anales de la Universidad del Norte 2.

1976. Geoglifos y tráfico de caravanas en el desierto chileno. En Homenaje al R. P. Gustavo Le Paige, s. j., pp. 147-201. Universidad del Norte, Antofagasta.

NUÑEZ, L. y T. DILLEHAY, 1979. Movilidad giratoria, armonía social y desarrollo en los Andes Meridionales, patrones de tráfico e interacción económica (ensayo). Universidad del Norte, Antofagasta.

OYARZUN, A., 1931. Tejidos de Calama. Revista Chilena de Historia y Geografía LXIX.

PORTILLO, F., 1976. Equivalencias de las técnicas de telar prehispánico de Perú. Cuadernos prehispánicos del Seminario Americanista, Universidad de Valladolid.

RYDEN, S., 1944. Contributions to the archaeology of the rio Loa Region. Gotemburgo.

ULLOA, L., 1982a. Evolución de la industria textil prehispánica en la zona de Arica. Chungara 8: 97-108.

1982b. Estilos decorativos y formas textiles de las poblaciones agromarítimas en el extremo norte de Chile. Chungara 8: 109-136. 